\title{
Plasmapheresis in Sepsis-induced Thrombotic Microangiopathy: A Case Series
}

\author{
Sushmita RS Upadhya ${ }^{1}$, Chakrapani Mahabala², Jayesh G Kamat ${ }^{3}$, Jayakumar Jeganathan ${ }^{4}$, Sushanth Kumar ${ }^{5}$, \\ Mayur V Prabhu ${ }^{6}$
}

\begin{abstract}
Introduction: Cytokines and granulocyte elastase produced in sepsis cleave a disintegrin and metalloprotease with thrombospondin type I motif 13 (ADAMTS13) and deplete its levels. By this mechanism, sepsis results in microangiopathic hemolytic anemia (MAHA) with thrombocytopenia. Hence, the hypothesis is that plasmapheresis may help in sepsis-induced thrombotic microangiopathy (sTMA), by removing the factors responsible for low levels of ADAMTS13. In tropical countries like India, the contribution of sepsis to intensive care unit (ICU) mortality is high; and hence, it is essential to look out for newer modalities of sepsis treatment. There is abundant literature on the use of plasmapheresis in sepsis but data on its use in STMA are limited, thus necessitating further research in this field.

Case description: This case series studies the outcomes of five patients admitted with sTMA in the ICU and attempts to evaluate the effectiveness of plasmapheresis in improving their outcomes. All patients diagnosed with sTMA and treated with plasmapheresis, between January 2016 and August 2018 at our tertiary care center, were selected for the study. The diagnosis of sepsis was based on sepsis-3 definition.

Results: Four different gram-negative organisms were found to have caused MAHA, with the commonest source being either urinary tract infection (UTI) or lower respiratory tract infection. Three of five patients required hemodialysis and two had disseminated intravascular coagulation (DIC). All five had good outcome and recovered well from the acute episode post plasmapheresis.

Discussion: In two of five patients, the initial smear was negative and hence the need for repeated examination of the peripheral blood smear should be kept in mind in cases of sTMAs. The median of the number of plasmapheresis sessions required in sTMA is six, which is lesser than that required for primary thrombotic thrombocytopenic purpura (TTP). Hence, the duration of central line placement and the risk of catheter-related complications are low. Based on the observations made in this case study, further exploratory studies are required to evaluate the efficacy of plasmapheresis in STMA secondary to tropical infections.

Keywords: Gram negative, Management, Microangiopathic hemolytic anemia, Peripheral smear, Plasmapheresis, Schistocyte, Sepsis, Sepsis and intensive care unit, Thrombotic microangiopathy.
\end{abstract}

Indian Journal of Critical Care Medicine (2020): 10.5005/jp-journals-10071-23374

\section{INTRODUCTION}

The thrombotic microangiopathies (TMAs) are a group of disorders that cause microvascular thrombosis resulting in thrombocytopenia and hemolytic anemia. The pathophysiology of primary thrombotic thrombocytopenic purpura (TTP) is occurrence of antibodies against ADAMTS13 which is a metalloprotease that cleaves ultra large von Willebrand factor (ULvWF) multimers. The accumulated multimers are the cause of the resultant microvascular thrombosis in the disease. Cytokines and granulocyte elastase produced in sepsis cleave ADAMTS13 and deplete its levels. By this mechanism, sepsis results in microangiopathic hemolytic anemia (MAHA) with thrombocytopenia. ${ }^{1}$ Hence, plasmapheresis may help in sepsis by removing the factors responsible for low levels of ADAMTS13 in sepsis-induced thrombotic microangiopathy (sTMA). ${ }^{2}$

Per the American Society for Apheresis guidelines, sepsis with multiorgan dysfunction is currently a level III, grade IIB recommendation for plasmapheresis. ${ }^{3}$ There is abundant literature on the use of plasmapheresis in sepsis but data on its use in sTMA are limited. Strong evidence for plasmapheresis in sTMA, available in the form of case reports or case series, ${ }^{4}$ has only been reported outside of India, and Indian literature regarding sTMA is relatively sparse.

Here we present a case series, a single-center experience of patients with sTMAs undergoing plasmapheresis. This case series studies the outcomes of five patients admitted with sepsis in the intensive care unit (ICU) and looks into the possibility of plasmapheresis as an effective treatment in cases of sTMA.

\footnotetext{
1,2,4 Department of Medicine, Kasturba Medical College, Mangalore, Manipal Academy of Higher Education, Manipal, India

${ }^{3}$ Department of Anaesthesia, Kasturba Medical College, Mangalore, Manipal Academy of Higher Education, Manipal, India

5,6 Department of Nephrology, Kasturba Medical College, Mangalore, Manipal Academy of Higher Education, Manipal, India
}

Corresponding Author: Chakrapani Mahabala, Department of Medicine, Kasturba Medical College, Mangalore, Manipal Academy of Higher Education, Manipal, India, Phone: +91 9448812207, e-mail: chakrapani.m@manipal.edu

How to cite this article: Upadhya SRS, Mahabala C, Kamat JG, Jeganathan J, Kumar S, Prabhu MV. Plasmapheresis in Sepsis-induced Thrombotic Microangiopathy: A Case Series. Indian J Crit Care Med 2020;24(3):195-199.

Source of support: Nil

Conflict of interest: None

\section{Case Description}

All patients who were diagnosed with sTMA between January 2016 and August 2018 at our tertiary care center were selected for the study. Those with other coexisting conditions which are proven to improve with plasmapheresis were excluded from the study. Sepsis was defined based on the sepsis-3 definition. ${ }^{5} \mathrm{~A}$ diagnosis of TMA was made based on the presence of schistocytes on peripheral 
smear that accompanied a sudden drop of hemoglobin and platelets along with end-organ damage. Five patients fulfilled the criteria and were diagnosed to have sTMA (Table 1). All the five patients were treated per the standard protocol, their vital parameters stabilized in the ICU, and antibiotics initiated as appropriate. They were supported with hemodialysis sessions and packed red blood cells and platelets were transfused as indicated. Despite this, they continued to deteriorate and hence plasmapheresis was initiated.

Each session of plasmapheresis was done over 1 and a half to 2 hours. Ultrafiltrate was based on the volume status of the patient. No heparin was given. About 1.5-2 $L$ of fresh frozen plasma was transfused back each time. One hundred milliliters of intravenous (IV) $20 \%$ human albumin in $500 \mathrm{~mL}$ of normal saline given per cycle and IV calcium gluconate $10 \mathrm{~mL}$ over 10 minutes was given twice each cycle. Routine dialysis machines were used with plasmapheresis filters (filtration technique).

According to the American Society of Apheresis, plasmapheresis should be continued till platelets are above 1.5 lakh for at least 2 days in cases of TTP, but no such recommendation exists for sTMAs. In our study, a positive response has been deemed as

- a brisk increase in platelet count by more than 20,000 in 2 days along with

- clinical improvement of the patient

in which case plasmapheresis was withheld the next day and patient was monitored.

The most common organ involved was the kidney, with all five patients having some degree of acute kidney injury. Three of 5 patients required hemodialysis in addition to plasmapheresis due to the severity of acute kidney injury. Two of the patients had disseminated intravascular coagulation (DIC) in addition to MAHA.

Only one patient had indirect hyperbilirubinemia, and all patients had significant lactate dehydrogenase (LDH) elevation with sudden drop in hemoglobin levels. Three of five patients had oliguria as defined by a urine output of $<500 \mathrm{~mL} /$ day. One patient had a hematoma at the catheter site and one had a minor reaction-shivering, post plasmapheresis. Only two patients were diagnosed with the first peripheral smear. The other three patients required two or more smears to establish a diagnosis of MAHA. Approximately seven sessions of plasmapheresis were needed to detect clinical improvement and an increase in platelet counts. All the patients had a good recovery from acute episode.

The table and graphs are representative of each patient's course in the hospital (refer Table 1 and Fig. 1).

\section{Discussion}

All our five patients with sTMA caused by predominantly gramnegative organisms required lesser number of plasmapheresis sessions than the conventional TMAs to show a good response. Considering that general ICU mortality in sepsis is greater than $20 \%,{ }^{6}$ and mortality related to TTP prior to the advent of plasmapheresis is about $72-94 \%,{ }^{7}$ the patients in this case series appear to have had a favorable outcome.

An important finding that we would like to highlight in this case series is the need for repeated smears to diagnose MAHA in our patients. Thrombotic thrombocytopenic purpura rarely presents with an initial negative smear. In our study, however, we found that often two or more blood smears were required to arrive at a diagnosis of MAHA. Thus, being a rare condition, sTMAs require a high degree of clinical suspicion and repeated smears to pursue the probability of STMA.
All five cases had involvement of the kidneys and the second commonly involved organs were the lungs and the brain. The younger the age of the patient, the lesser was the morbidity denoted by number of days of stay in the ICU and lesser the total hospital stay. Four of them were diagnosed with TMA early on in the disease (within the first 4 days of onset of sepsis) and these patients had good functional outcome. The fifth patient, however, was diagnosed on the ninth day after onset of sepsis and she recovered initially but later progressed to chronic kidney disease. She also required the maximum number of sessions of plasmapheresis and had the highest number of days of hospital stay. Being a case series of only five cases, conclusions cannot be drawn from the above but the possibility of better outcomes with quicker recognition of the entity and faster initiation of treatment with plasmapheresis should definitely be looked into.

Sepsis is known to be a condition with high mortality rates $\left(>20 \%{ }^{6}\right)$, and a systematic review and meta-analysis done in $2014^{8}$ does not show any benefit of plasmapheresis in sepsis. However, there also exist studies denoting the efficacy of plasmapheresis in sepsis and septic shock. A study published in the infectious diseases journal in 1993, on the treatment of primary septic shock in humans shows a $4-25 \%$ relative benefit with plasmapheresis in sepsis. ${ }^{9}$ Another study on plasma exchange in septic shock and acute renal failure demonstrates a fourfold increase in survival compared to historical controls. ${ }^{10}$ Incidentally, all five of our patients had renal failure secondary to STMA and all of them had a good outcome post plasmapheresis.

Plasmapheresis has also been shown to be beneficial in other secondary TMAs-Bennett et al., ${ }^{11}$ presented a case of ticlopidineinduced TMA improving with plasmapheresis. Another study emphasizes "the role of plasmapheresis in critical illness" and the growing evidence that plasmapheresis is useful in systemic inflammation induced TTPs too. ${ }^{12}$

There are also a few studies on sTMAs which show benefit with plasmapheresis. One published in $2005^{4}$ states that plasma exchange in adults with TMAs triggered by infections was independently associated with lower mortality, regardless of disease severity. Another study by Darmon et al. ${ }^{13}$ demonstrates a significantly lower rate of organ failure scores from day 3 to day 9 and improved outcomes in secondary TMAs with plasmapheresis. A guideline published in the Journal of Clinical Apheresis by Padmanabhan et al. shows pneumococcal hemolytic uremic syndrome and enterotoxigenic Escherichia coli to be grade IIIC recommendation for plasmapheresis. However, there is no mention regarding gramnegative tropical infections with other organisms resulting in TMA and the benefit of plasmapheresis in such instances. ${ }^{3}$ The guideline also mentions the mean number of sessions of plasmapheresis as 12 , which is more than what we have observed in our case series of TMAs caused by gram-negative organisms. Contrary to this study and western literature of organisms causing sepsis, ${ }^{14}$ predominantly gram-negative organisms were isolated upon culture in our study. Hence, these studies cannot be directly extrapolated to the Indian scenario. More randomized controlled trials (RCTs) are thus needed to analyze the efficacy of plasmapheresis in gram-negative organism induced TMAs, which is the more predominant cause of sepsis in India. ${ }^{15}$

Differentiating MAHA from DIC is based on the presence of evidence of fibrinolysis with elevated coagulation parameters which points toward a diagnosis of DIC. Hemolytic anemia with a sudden drop in hemoglobin and platelet count points toward a diagnosis of MAHA. Disseminated intravascular coagulation 
Table 1: Case details of studied patients

\begin{tabular}{|c|c|c|c|c|c|}
\hline & Case 1 & Case 2 & Case 3 & Case 4 & Case 5 \\
\hline Age & 73 years & 64 years & 50 years & 35 years & 29 years \\
\hline Sex & Male & Male & Female & Male & Female \\
\hline Total hospital days & 25 days & 18 days & 58 days & 16 days & 11 days \\
\hline No. of days of ICU stay & 17 days & 8 days & 12 days & 8 days & 4 days \\
\hline Diagnosis & Urosepsis & $\begin{array}{l}\text { Aspiration pneumo- } \\
\text { nia following cerebro- } \\
\text { vascular accident }\end{array}$ & $\begin{array}{l}\text { LRTI with acute kid- } \\
\text { ney injury (AKI) and } \\
\text { sepsis/ischemic heart } \\
\text { disease and systemic } \\
\text { hypertension }\end{array}$ & $\begin{array}{l}\text { Escherichia coli sepsis/ } \\
\text { foot ulcer/hepatitis E }\end{array}$ & $\begin{array}{l}\text { Peripartum urosepsis } \\
\text { with pregnancy- } \\
\text { induced hypertension }\end{array}$ \\
\hline \multirow[t]{2}{*}{$\begin{array}{l}\text { Sepsis causing organ- } \\
\text { ism }\end{array}$} & $\begin{array}{l}\text { Enterococcus } \\
\text { faecium-urine } \\
\text { culture }\end{array}$ & \multirow{2}{*}{$\begin{array}{l}\text { Pseudomonas, } \\
\text { Staphylococcus aureus } \\
\text { in endotracheal tube } \\
\text { aspirate }\end{array}$} & None isolatable & \multirow{2}{*}{$\begin{array}{l}\text { Escherichia coli in } \\
\text { both blood culture } \\
\text { and wound swab } \\
\text { culture }\end{array}$} & \multirow{2}{*}{$\begin{array}{l}\text { None isolatable- } \\
\text { history and } \\
\text { investigation } \\
\text { suggestive of UTI }\end{array}$} \\
\hline & $\begin{array}{l}\text { Pan-resistant } \\
\text { Klebsiella in blood } \\
\text { and urine }\end{array}$ & & $\begin{array}{l}\text { Chest X-ray-right } \\
\text { lower zone opacity }\end{array}$ & & \\
\hline Organs involved & Kidneys & Kidneys, lungs, brain & Kidney & $\begin{array}{l}\text { Kidney, encephalopa- } \\
\text { thy, upper gastroin- } \\
\text { testinal system }\end{array}$ & Kidney, uterus, lungs \\
\hline $\begin{array}{l}\text { Indirect hyperbiliru- } \\
\text { binemia }\end{array}$ & Absent & Present & Not available & Absent & Absent \\
\hline $\begin{array}{l}\text { Fibrin degradation } \\
\text { product }\end{array}$ & Positive & Not done & Not done & Positive & Not done \\
\hline $\begin{array}{l}\text { LDH elevation in units } \\
\text { per liter }\end{array}$ & 515 & 420 & 715 & 3,429 & 4,207 \\
\hline \multirow[t]{3}{*}{$\begin{array}{l}\text { Complications during } \\
\text { stay of patient }\end{array}$} & \multirow[t]{3}{*}{$\begin{array}{l}\text { Hematuria, hypona- } \\
\text { tremia, left pleural } \\
\text { effusion }\end{array}$} & \multirow[t]{3}{*}{$\begin{array}{l}\text { Multiple acute in- } \\
\text { farcts in brain, oligu- } \\
\text { ria, secondary UTI }\end{array}$} & \multirow[t]{3}{*}{$\begin{array}{l}\text { Post resolution of } \\
\text { MAHA with throm- } \\
\text { bocytopenia, she } \\
\text { developed UTI with } \\
\text { urosepsis and ICU } \\
\text { care }\end{array}$} & $\begin{array}{l}\text { Hypoxia with } \\
\text { metabolic acidosis. } \\
\text { oliguria with nil } \\
\text { output on 8th and } \\
\text { 9th day of admission. } \\
\text { Hyponatremia. } \\
\text { Chicken pox in the } \\
\text { preceding week }\end{array}$ & \multirow[t]{3}{*}{$\begin{array}{l}\text { Couvelaire uterus } \\
\text { resulting in cesarean } \\
\text { section-baby } \\
\text { expired on first day } \\
\text { of life. Acute kidney } \\
\text { injury with oliguria }\end{array}$} \\
\hline & & & & $\begin{array}{l}\text { Persistent oral bleed, } \\
\text { intubated in view of } \\
\text { altered sensorium }\end{array}$ & \\
\hline & & & & Hepatitis E & \\
\hline $\begin{array}{l}\text { Catheter site } \\
\text { complications }\end{array}$ & Nil & $\begin{array}{l}\text { Hematoma at cath- } \\
\text { eter site }\end{array}$ & Nil & Nil & Nil \\
\hline $\begin{array}{l}\text { Plasmapheresis- } \\
\text { related complications }\end{array}$ & Nil & Nil & Nil & $\mathrm{Nil}$ & $\begin{array}{l}\text { Chills-sub- } \\
\text { sided promptly on } \\
\text { medication }\end{array}$ \\
\hline \multirow[t]{2}{*}{$\begin{array}{l}\text { Number of peripheral } \\
\text { smears done with } \\
\text { reports }\end{array}$} & $\begin{array}{l}\text { 1st smear-negative } \\
\text { for schistocytes- } \\
\text { neutrophilic } \\
\text { leukocytosis with left } \\
\text { shift }\end{array}$ & 1st smear-MAHA & 1st smear-MAHA & $\begin{array}{l}\text { 1st smear- } \\
\text { negative for } \\
\text { schistocytes-79\% } \\
\text { neutrophils, left shift }\end{array}$ & $\begin{array}{l}\text { 1st smear-negative } \\
\text { for schistocytes-- } \\
\text { shift to left with } \\
\text { neutrophilic leu- } \\
\text { kocytosis and toxic } \\
\text { granules }\end{array}$ \\
\hline & 2nd smear-MAHA & $\begin{array}{l}\text { Two repeat smears } \\
\text { showed persistent } \\
\text { schistocytes. }\end{array}$ & & 2nd smear-MAHA & 2nd smear-MAHA \\
\hline $\begin{array}{l}\text { Days required after } \\
\text { onset of sepsis to } \\
\text { diagnose MAHA }\end{array}$ & 4 days & 2 days & 9 days & 2 days & 3 days \\
\hline $\begin{array}{l}\text { Number of sessions of } \\
\text { plasmapheresis }\end{array}$ & 7 sessions & 6 sessions & 8 sessions & 6 Sessions & 5 sessions \\
\hline Overall outcome & Recovered & Recovered & $\begin{array}{l}\text { Recovered clinically } \\
\text { from initial episode } \\
\text { but developed } \\
\text { chronic kidney failure } \\
\text { as sequelae }\end{array}$ & Recovered & Recovered \\
\hline
\end{tabular}



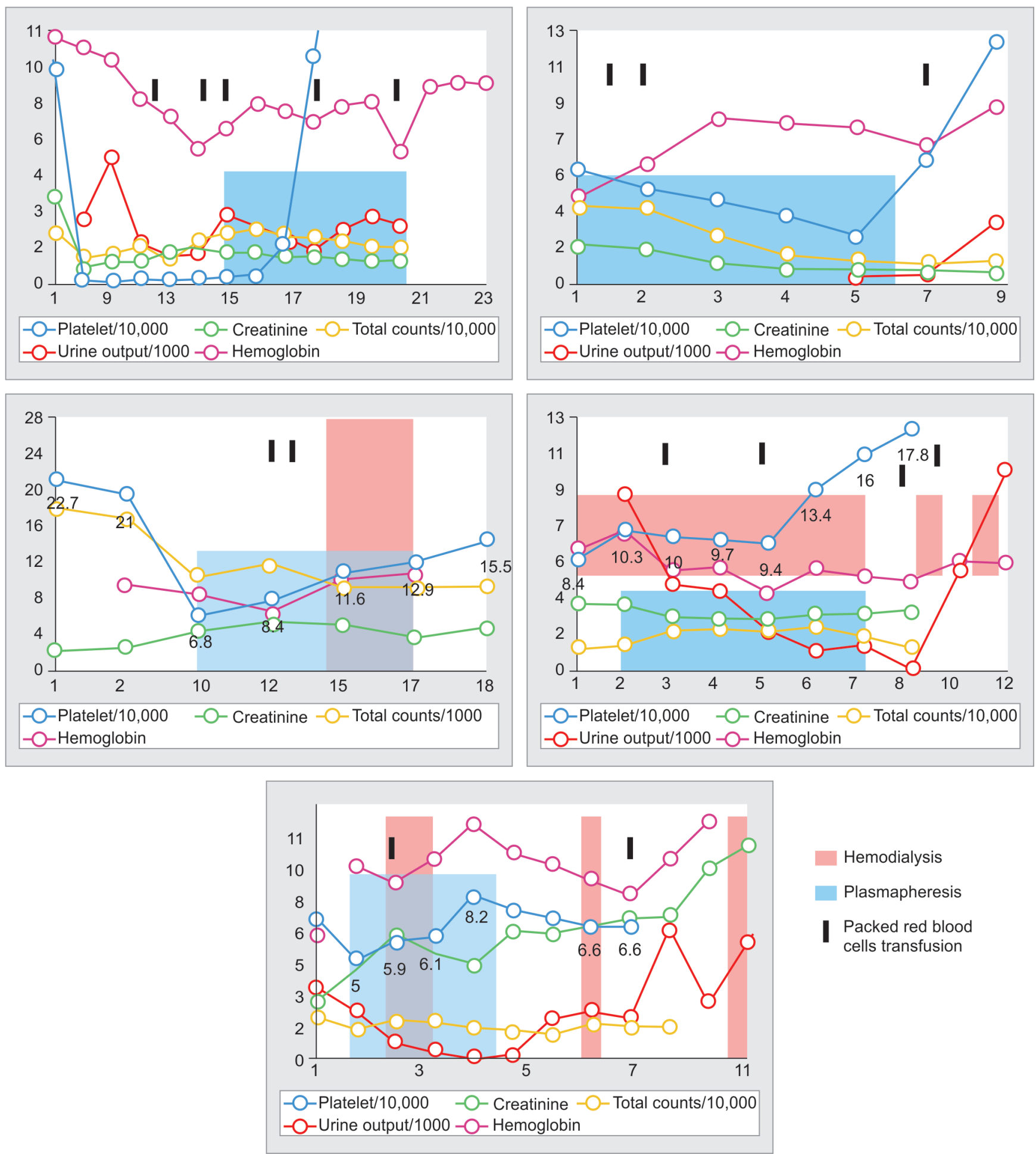

Hemodialysis

Plasmapheresis

Packed red blood

cells transfusion

Fig. 1: Trend observed in laboratory parameters and urinary output, in relation to plasmapheresis and dialysis sessions

involves altered coagulation parameters such as activated partial thromboplastin time, prothrombin time, and international normalized ratio unlike MAHA. Also, the sudden drop in platelets, often observed in MAHA, is usually not a prominent feature of DIC. In our study, two patients had a positive fibrin degradation product value in addition to the presence of MAHA. Hence, even if a diagnosis of DIC has been made in sepsis, MAHA should still be kept in mind as a possibility in the presence of sudden drop in hemoglobin and platelet counts.

Another observation made here is the absence of indirect hyperbilirubinemia in three of the five cases in this study, despite evidence in favor of a hemolytic anemia. Hence, absence of an elevated indirect bilirubin need not necessarily point toward an alternative diagnosis. 
Despite having case reports, case series, and a few studies demonstrating the efficacy of plasmapheresis in sTMA, it has not yet been officially declared to be a modality of treatment for the same. This is because there are no high-quality RCTs proving its efficacy. Another important reason is the possibility of fatal complications secondary to plasmapheresis. Well-recognized complications are catheter-related sepsis, catheter obstruction, hypotension, hypoxia, vasovagal, and anaphylactic attacks. In our study, we only had one patient with a mild allergic reaction to the transfusion that promptly resolved on administering IV corticosteroids and pheniramine. Also, the huge volumes of plasma transfusion might cause citrate overload-related complications which were prevented by the administration of calcium gluconate.

However, a study by Couriel et al. ${ }^{16}$ presents the incidence of severe complications of plasmapheresis as only $1 \%$-all being related to catheter site. There are studies that deem catheter insertion to be safe even with platelet counts 40,000 if done atraumatically under ultrasonography guidance. ${ }^{17}$ As mentioned above, the duration of catheter placement is considerably lower in our study of sTMA compared to other similar studies. Hence, the duration of central line placement would be lesser, decreasing the rate of incidence of the above-mentioned complications.

The limitations of the study are:

- Schistocytes greater than or equal to 2 per high-power field is suggestive of MAHA. In our study, the schistocytes reported in the smears were not graded. However, all smear impressions were reported by our pathologists to be suggestive of MAHA.

- Other possible etiologies of secondary TMAs cannot be confidently ruled out. One patient had the TMA post cesarean section. She had a history of urinary tract infection (UTI) for 1 week prior to delivery but coexistence of other pregnancy-induced TMAs cannot be confidently ruled out here. However, pregnancy-induced TMAs usually resolve within 36 hours of delivery, and the persistence of symptoms and thrombocytopenia even 3-4 days after delivery makes a differential of sTMA more likely.

- The ADAMTS13 levels are usually $<10 \%$ in TTP with levels of $10-60 \%$ in sTMAs. Plasma levels of ADAMTS13 were not measured in our study to confirm the presence of TMA. Nguyen and $\mathrm{Han}^{2}$ states in a study that the laboratory tests for ADAMTS13 activity, vWF activity and detection of ULvWF are difficult to obtain in a timely manner to make clinical decisions. Hence, we are relying on simple lab tests to suggest the presence of TMA such as blood smear schistocytes, LDH elevation, clinical data, coagulopathy, and multiorgan failure to make decisions for plasma exchange.

In our case series, we find plasmapheresis to be beneficial in sTMAs in tropical infections. However, good quality RCTs are needed to establish the efficacy of plasmapheresis in sTMAs in tropical infections. Sepsis-induced TMA should hence be suspected in patients with sepsis and rapidly falling hemoglobin and platelets, and the search for a TMA should be made even if it was not evident initially.

\section{References}

1. Ono T, Mimuro J, Madoiwa S, Soejima K, Kashiwakura Y, Ishiwata A, et al. Severe secondary deficiency of von Willebrand factor-cleaving protease (ADAMTS13) in patients with sepsis-induced disseminated intravascular coagulation: its correlation with development of renal failure. Blood 2006;107(2):528-534. DOI: 10.1182/blood-2005-03-1087.

2. Nguyen TC, Han YY. Plasma exchange therapy for thrombotic microangiopathies. Organogenesis 2011;7(1):28-31. DOI: 10.4161/ org.7.1.14027.

3. Schwartz J, Padmanabhan A, Aqui N, Balogun RA, Connelly-Smith $\mathrm{L}$, Delaney $\mathrm{M}$, et al. Guidelines on the use of therapeutic apheresis in clinical practice-evidence-based approach from the writing committee of the american society for apheresis: the seventh special issue. J Clin Apher 2016;31(3):149-162. DOI: 10.1002/jca.21470.

4. Pene F, Vigneau C, Auburtin M, Moreau D, Zahar JR, Coste J, et al. Outcome of severe adult thrombotic microangiopathies in the intensive care unit. Intensive Care Med 2005;31(1):71-78. DOI: 10.1007/ s00134-004-2505-0.

5. Singer M, Deutschman CS, Seymour CW, Shankar-Hari M, Annane D, Bauer $M$, et al. The third international consensus definitions for sepsis and septic shock (Sepsis-3). JAMA 2016;315(8):801-810. DOI: 10.1001/ jama.2016.0287.

6. Sakr Y, Jaschinski U, Wittebole X, Szakmany T, Lipman J, ÑamendysSilva SA, et al. Sepsis in intensive care unit patients: worldwide data from the intensive care over nations audit. Open Forum Infect Dis 2018;5(12):ofy313. DOI: 10.1093/ofid/ofy313.

7. Chaturvedi S, Abbas H, Mccrae KR. Increased morbidity during long-term follow-up of survivors of thrombotic thrombocytopenic purpura. Am J Hematol 2015;90(10):E208. DOI: 10.1002/ajh.24138.

8. Rimmer E, Houston BL, Kumar A, Abou-Setta AM, Friesen C, Marshall $J C$, et al. The efficacy and safety of plasma exchange in patients with sepsis and septic shock: a systematic review and meta-analysis. Crit Care 2014;18(6):699. DOI: 10.1186/s13054-014-0699-2.

9. Gårdlund B, Sjölin J, Nilsson A, Roll M, Wickerts C-J, Wikstrom $B$, et al. Plasmapheresis in the treatment of primary septic shock in humans. Scand J Infect Dis 1993;25(6):757-761. DOI: 10.3109/00365549309008575.

10. Stegmayr B, Abdel-Rahman EM, Balogun RA. Septic shock with multiorgan failure: from conventional apheresis to adsorption therapies. Semin Dial 2012;25(2):171-175. DOI: 10.1111/j.1525139X.2011.01029.x.

11. Bennett CL, Weinberg PD, Rozenberg-Ben-Dror K, Yarnold PR, Kwaan $\mathrm{HC}$, Green D. Thrombotic thrombocytopenic purpura associated with ticlopidine. A review of 60 cases. Ann Intern Med 1998;128(7):541-544. DOI: 10.7326/0003-4819-128-7-199804010-00004.

12. Nguyen TC, Kiss JE, Goldman JR, Carcillo JA. The role of plasmapheresis in critical illness. Crit Care Clin 2012;28(3):453-468. DOI: 10.1016/ j.ccc.2012.04.009.

13. Darmon M, Azoulay E, Thiery G, Ciroldi M, Galicier L, Parquet $N$, et al. Time course of organ dysfunction in thrombotic microangiopathy patients receiving either plasma perfusion or plasma exchange. Crit Care Med 2006;34(8):2127-2133. DOI: 10.1097/ 01.CCM.0000227659.14644.3E.

14. Mayr FB, Yende S, Angus DC. Epidemiology of severe sepsis. Virulence 2014;5(1):4-11. DOI: 10.4161/viru.27372.

15. Chatterjee S, Bhattacharya M, Todi S. Epidemiology of adultpopulation sepsis in India: a single center 5 year experience. Indian J Crit Care Med 2017;21(9):573-577. DOI: 10.4103/ijccm.IJCCM_240_17.

16. Couriel D, Weinstein R. Complications of therapeutic plasma exchange: a recent assessment. J Clin Apher 1994;9(1):1-5. DOI: 10.1002/jca.2920090102.

17. Doerfler ME, Kaufman B, Goldenberg AS. Central venous catheter placement in patients with disorders of hemostasis. Chest 1996;110(1):185-188. DOI: 10.1378/chest.110.1.185. 